\title{
A MODALIDADE EPISTÊMICA NOS DISCURSOS POLÍTICOS
}

\author{
GUIRADELLI, Lisângela A. ${ }^{1}$ \\ NOGUEIRA, Livia Maria de Souza Maciel ${ }^{2}$ \\ SILVA, Janaina Dantas Ferreira da ${ }^{2}$ \\ SILVA, Priscila Gomes da ${ }^{2}$
}

\begin{abstract}
RESUMO: A presente pesquisa tem por objetivo analisar as manifestações da modalidade epistêmica na língua portuguesa, especificamente no português escrito do Brasil, visto que a modalidade epistêmica está relacionada ao comprometimento do falante com a verdade do enunciado. As análises das funções comunicativas das estruturas gramaticais modalizadoras foram feitas em discursos políticos retirados de sites especializados, proferidos pelo atual presidente da República Luiz Inácio Lula da Silva, em diferentes momentos de seu governo. A escolha deste corpus se justifica pelo fato de os discursos políticos assumirem um papel importante na persuasão e também pelo fato de favorecerem o surgimento de valores epistêmicos. Esse trabalho se desenvolve dentro de uma perspectiva funcionalista da linguagem, já que o entendimento de uma estrutura só poderá ser atingido se consideradas suas funções semânticas e comunicativas.
\end{abstract}

Palavras-chave: Modalidade. Epistêmico. Funcionalismo. Discurso político

SUMMARY: The purpose of this research is to analyze epistemic modality manifestations in Portuguese Language, specifically in Brazilian spoken language, since epistemic modality is related to speaker's commitment with statements of truth. The analysis of the communicative functions of grammatical structures have been done in politician discourses, extracted from specialized sites, pronounced by the present Brazilian President Luiz Inácio Lula da Silva in different moments of his government. The use of this kind of corpus is justified by the fact that these discourses assume an important role in persuasion and because these discourses support the manifestation of epistemic values. This work is developed within a functionalist perspective of language, since the understanding of a structure can only be reach if its semantic and communicative functions will be considered.

Keywords: Modality. Epistemic. Functionalism. Politician discourse

\section{INTRODUÇÃO}

Neste trabalho analisaremos as manifestações da modalidade epistêmica na língua portuguesa, especificamente no português escrito do Brasil, visto que a modalidade epistêmica está relacionada ao comprometimento do falante com a verdade do enunciado.

Considerando que as modalidades não estão restritas a uma classificação sintática, procuraremos neste estudo fazer uma análise mais ampla que englobará a sintaxe, a semântica e a pragmática. Por isso, adotamos uma perspectiva funcional da linguagem, que engloba os

\footnotetext{
${ }^{1}$ Doutoranda em Estudos Lingüísticos pela Universidade Estadual Paulista Julio de Mesquita Filho - UNESP. Professora da Faculdade de Filosofia Ciências e Letras de Ituverava FE/FFCL e da Universidade de Franca UNIFRAN.

${ }^{2}$ Licenciatura Plena em Letras FE/FFCL- Ituverava.
} 
aspectos sintáticos, semânticos e pragmáticos de forma integrada e que leva em consideração a competência comunicativa dos falantes.

Nesta pesquisa serão utilizados como corpus discursos políticos, retirados de sites especializados, pronunciados pelo atual presidente da República Luiz Inácio Lula da Silva, em diferentes momentos de seu governo. A escolha deste corpus se justifica pelo fato de os discursos políticos assumirem um papel importante na persuasão e também pelo fato de favorecerem o surgimento de valores epistêmicos.

Em um primeiro momento são mostradas algumas definições e conceitos para a modalidade, além de serem apresentados alguns pressupostos sobre o discurso político; em seguida, são analisados os efeitos de sentido reproduzidos pelos modalizadores nos discursos selecionados e observada a função que as manifestações do saber exercem na organização discursiva dos textos analisados e, por último, a apresentação dos resultados e as reflexões obtidas neste trabalho.

\section{PRESSUPOSTOS TEÓRICOS}

\subsection{A MODALIDADE}

Modalidade é a qualificação que caracteriza a atitude do emissor no ato da fala, podendo este comprometer-se ou não com o enunciado. As noções de subjetividade e comprometimento são, portanto, fundamentais para a definição de modalidade, como aponta Coracini (1991, p. 113) que diz que a "Modalidade é a expressão da subjetividade de um enunciador que assume com maior ou menor força o que enuncia, ora comprometendo-se, ora afastando-se, seguindo normas determinadas pela comunidade em que se insere."

Conforme aponta Neves (2006, p.152), "se a modalidade é, essencialmente, um conjunto de relações entre o locutor, o enunciado e a realidade objetiva, é cabível propor que não existam enunciados não modalizados." Ainda segundo a autora, do ponto de vista comunicativo-pragmático, a modalidade pode ser considerada uma categoria automática, pois para ela não há como conceber que o falante deixe de marcar de algum modo o seu enunciado em termos da verdade do fato expresso, bem como que deixe de imprimir no enunciado certo grau de certeza sobre essa marca.

De acordo com Quirk (1985, p.219), “modalidade pode ser definida como a maneira pela qual o significado de uma oração é qualificado de forma a refletir o julgamento do falante sobre a probabilidade de ser verdadeira a proposição por ela expressa." 
No entanto, como se pode observar, a tradição da Lingüística não tem tratado a modalização dos enunciados dessa maneira. Ducrot (1993 apud NEVES, 2006) diz que o nome modalidade foi dado de início às expressões que remetem de modo mais, ou menos, aproximado à oposição estabelecida pela Lógica antiga entre conceitos de "possível", de "real" e de "necessário". Nessa perspectiva, esses são os conceitos tidos inicialmente como modalidades, e a tendência é ver o real como uma espécie de modalidade zero. De acordo com Neves (2006), as ocorrências abaixo exemplificam essa tendência:

(1) Falso foi o seu discurso. aparece como menos modal do que

(2) É possível que falso tenha sido o seu discurso.

e menos ainda que

(3) É necessário que falso tenha sido o seu discurso.

Por outro lado, a simples afirmação de um fato como ocorre em:

(4) Na próxima semana ele virá.

é sentida como menos modal do que a afirmação de uma obrigação, como

(5) Na próxima semana ele deverá vir.

ou de uma crença, como

(6) Acho que na próxima semana ele virá.

Considerando o significado da oração, Quirk (1985) divide a modalidade em dois tipos: 1) as que relacionam "permissão", "obrigação" e "volição" e envolvem algum tipo de controle humano sobre os eventos e 2) as relacionadas à "probabilidade", "necessidade" e "prognóstico", que inicialmente não envolvem um controle humano sobre os eventos, mas um julgamento humano do que é possível ou não acontecer.

As modalidades têm sido tratadas por diferentes estudiosos de acordo com diversos pontos de vista, ora privilegiando a sintaxe, ora a semântica e ora a pragmática. E têm sido tradicionalmente classificadas segundo o campo semântico no qual se assenta a avaliação feita pelo falante. Ainda que nem sempre essa tipologia seja consensual, quatro são as modalidades mais freqüentemente identificadas nos muitos estudos sobre o tema: modalidades alética, volitiva, deôntica e epistêmica.

\subsection{OS TIPOS DE MODALIDADE}

A modalidade alética, ou lógica, está relacionada exclusivamente com a verdade necessária ou contingente das proposições: 
(7) A água pode ser encontrada em estado líquido, sólido e gasoso.

(8) Mas, se a Terra é uma bola e está girando todo dia perto do sol, não deve ser verão em toda a Terra?

A modalidade alética tem relação com o mundo ontológico, refletindo a escala lógica que vai do necessário ao impossível, passando pelo possível e pelo contingente. A modalidade alética, dessa forma, trata de uma verdade incontestável.

A modalidade volitiva diz respeito à necessidade e à possibilidade, relacionadas aos desejos do falante (no fundo, uma necessidade deôntica):

(9) Desta vez o título deve ser nosso.

(10) Eu quero utilizar aquilo para fazer alguma coisa, além de guardar papéis velhos e carros velhos que estão armazenados lá. Não tem sentido aquilo ficar na mão da União. (D6)

A modalidade deôntica, por sua vez, está relacionada com obrigações e permissões:

(11) É preciso produzir mais e distribuir melhor. O Brasil, como potência agrícola, está empenhado em aumentar sua produção. (D5)

(12) Ângela é preciso tomar cuidado e não exagerar: você não deve estragar Mário.

A modalidade deôntica está condicionada por traços lexicais específicos ligados ao falante e, de outro lado, implica que o ouvinte aceite o valor da verdade do enunciado para executá-lo.

Segundo Neves (2006), a modalidade epistêmica está relacionada com a necessidade e a probabilidade epistêmicas, que são expressas por proposições contingentes, isto é, que dependem de como o mundo é. O conhecimento do falante sobre o mundo é representável como um conjunto de proposições.

(13) Possivelmente, todos nós sonhamos há muito tempo que o Brasil precisaria ser dotado de um modelo de infra-estrutura que pudesse permitir que o Brasil andasse mais rápido,(...). (D3)

Para Lyons (1977 apud GUIRALDELLI, 2004), um enunciado epistemicamente modalizado é aquele no qual o falante qualificará de forma explícita seu comprometimento com a verdade da proposição. Tal modalidade é subdividida em objetiva e subjetiva. Os enunciados modalizados na forma subjetiva, segundo Lyons, são afirmações de rumor e opinião como em:

(14) Nesse momento a votação pode estar sendo feita. 
Mas se esse mesmo enunciado for interpretado de maneira objetiva, será a afirmação de um fato.

(15) Nesse momento a votação está sendo feita.

De acordo com Lyons, quando o falante qualifica seu compromisso com a verdade de forma objetiva, o enunciado expressa um conhecimento que é geralmente aceito ou que é cientificamente comprovável. Apesar da diferença estabelecida entre modalidade epistêmica objetiva e subjetiva, por meio da natureza da força ilocucionária, Lyons admite que tal distinção não pode ser percebida com facilidade no uso diário da língua. Por outro lado, a distinção entre modalidade epistêmica e deôntica é considerada pelo autor como “óbvia".

Como se observa, pode-se dizer que os tipos de modalidade tradicionalmente reconhecidos são um tanto diferentes para diferentes autores. A complexidade do processo de modalização exige, então, que esse fenômeno seja estudado sob um ponto de vista de uma teoria que considere aspectos sintáticos, semânticos e pragmáticos de maneira integrada. Por essa razão, estudamos a modalidade dentro do funcionalismo holandês que estuda a língua em uso e como forma de interação social. Segundo o ponto de vista funcional, uma língua natural deve ser considerada, primeiramente, “como um instrumento de interação social por meio do qual seres humanos podem se comunicar uns com os outros e, assim, influenciar mutuamente as atividades mentais e práticas”.(DIK, 1989, p.1)

Em nossa pesquisa dá-se ênfase à modalidade epistêmica, por se tratar de uma modalidade que se acentua no eixo do saber, do conhecimento e expressa a avaliação do falante sobre a probabilidade, a possibilidade pragmática de ocorrência de um estado-de-coisa situada a um contínuo que vai do certo ao possível.

\subsection{A MODALIDADE EPISTÊMICA}

Sabendo que a modalidade epistêmica é a modalidade que possui certo grau de comprometimento com o enunciado e se relaciona com o conhecimento, o saber que se tem sobre um estado-de-coisas, podemos afirmar que a todo momento, de forma direta ou indireta, estamos utilizando marcadores de modalização, pois a modalização revela a atitude do falante perante seu enunciado. É a partir da modalização que se pode verificar o modo como aquilo que se diz é dito (DALL'AGLIO-HATTNHER, 1996).

A modalidade epistêmica pode ser percebida tanto no ato da fala quanto no da escrita e se destacar, sobretudo, em discursos científico, religioso e político. Observando que essa 
modalidade está relacionada com a necessidade e a probabilidade, ela se torna importante nos discursos citados acima, como veremos a seguir.

Analisamos a manifestação da modalidade epistêmica em discursos políticos, e utilizamos meios gramaticais e lexicais para demonstrar, assim, o comprometimento do falante.

\section{O DISCURSO POLÍTICO E A CONSTITUIÇÃO DO CóRPUS}

\subsection{O DISCURSO POLÍTICO}

Conforme o Dicionário Brasileiro Globo: discurso é o conjunto ordenado de frases pronunciado em público, ou escritas para serem lidas em público. Segundo Fiorin (1988, p.16): "O discurso não é, portanto, o lugar de liberdade e da criação, mas é o lugar de reprodução dos discursos das classes e das frações de classes". O autor considera o discurso como o lugar social.

Ao estudar o discurso político deve-se observar a posição-sujeito do enunciador e o meio social em que ele estará proferindo sua fala, pois na tentativa de convencer o povo de que ele, como político responsável e competente, é merecedor de credibilidade ele modifica a informação pragmática do seu público-alvo. Segundo Guiraldelli (2004), a palavra, sendo instrumento legítimo de poder, ao ser usada pelo falante no discurso político, assume valores que o falante acredita estar presente no ouvinte a fim de persuadi-lo com a intenção de que seu ouvinte aceite e siga suas idéias.

De acordo com Fantinati (1990, p.2), “a linguagem do discurso político não é simplesmente uma linguagem técnica que se possa caracterizar univocamente. Como a própria política, ela é plurissignificativa, penetra todas as esferas da vida social e se ajusta às diferentes tarefas requeridas por ela".

A modalização fundamental do discurso político é o poder, havendo assim dois componentes: um fazer interpretativo e um fazer persuasivo. $\mathrm{O}$ primeiro trata da realidade e o segundo como a fala irá agir sobre um público-enunciatário. Por esses dois componentes dizse que o discurso político se produz a partir da realidade e fala do que realmente ocorre.

Segundo Fiorin (1988, p.145), "o discurso político tem a finalidade de fazer-fazer, ou seja, seu programa é conquistar "poder". Avaliando a frase de Fiorin e a posição dos políticos na sociedade, podemos crer na busca do poder e na tentativa de satisfazer às reivindicações 
das classes sociais presentes nas falas políticas. Utilizando-se de uma linguagem culta e de argumentos científicos, o discurso político precisa determinar certeza sobre a possibilidade ao prometer algo. Assim, como cada candidato possui diferentes propostas, vota-se na credibilidade de alguém e não nos objetivos do partido.

Os discursos políticos são altamente argumentativos, pois pretendem convencer o interlocutor da validade do que dizem e procedem retórica e linguisticamente de acordo com esse objetivo. Em alguns tipos de discurso político, o falante ilude seu ouvinte e graças à força persuasiva e à manipulação psicológica dos argumentos, o ouvinte é conduzido à impossibilidade de raciocinar e aceitar passivamente as propostas do locutor.

De acordo com Osakabe (1979), para analisar um discurso é preciso considerar de antemão as condições de produção para que se possa fazer uma observação interna de cada realidade discursiva. Segundo o autor, o discurso ultrapassa as explicações lingüísticas, pois o discurso apresenta um sistema de significações ideológicas e se cristaliza em motivações históricas. Osakabe considera que também compõem as condições de produção do discurso a imagem que o locutor tem do referente e a imagem que pressupõe que o ouvinte tem desse referente.

No discurso político, segundo Osakabe, os atos argumentativos podem ser distinguidos em ato de promover (falante promove o ouvinte a lugar de decisões, mesmo que esse ouvinte não tenha condições reais de decidir), ato de envolver (falante envolve seu ouvinte de tal maneira a anular a possibilidade de crítica da parte do ouvinte) e ato de engajar (caberá ao ouvinte solucionar o problema criado no ato de envolvimento ou aderir a um ponto de vista descrito nesse ato).

Observamos que o discurso político se insere em situações tensas e conflituosas, já que este se encontra em competição declarada com outros políticos e partidos. Além disso, o ouvinte é visto como desconfiado e que não se deixa levar mais por simples promessas, portanto o enunciador procura passar para seu ouvinte que ele, como político, é diferente, verdadeiro e assim procura transmitir credibilidade.

O conhecimento partilhado, ou o interesse sobre determinado assunto, entre enunciador/enunciatário nos discursos políticos analisados poderá apontar diferenças nos usos dos modalizadores como veremos. Essa hipótese e informações acima levantadas sobre o discurso político são verificadas na análise do corpus no capítulo seguinte. 


\subsection{CONSTITUIÇÃO DO CÓRPUS}

Nesta pesquisa, analisamos seis discursos proferidos pelo atual Presidente da República, Luiz Inácio Lula da Silva. Todos os discursos foram retirados de sites especializados ${ }^{3}$. A saber:

- Discurso de posse, pronunciado em 01/01/2003, no qual denominamos D1.

- Cerimônia de entrega dos cartões do programa Bolsa Família, pronunciado em 04/06/2005, no qual denominamos D2.

- Construção da Variante Ferroviária Litorânea Sul, pronunciado em 24/01/2006, no qual denominamos D3.

- Discurso de posse, pronunciado em 01/01/2007, no qual denominamos D4.

- Cerimônia de abertura da $3^{a}$ Conferência Nacional das Cidades, pronunciado em 26/11/2007, no qual denominamos D5.

- Reunião de Alto Nível da FAO sobre Segurança Alimentar, Mudanças Climáticas e Bioenergia, pronunciado em 03/06/2008, no qual denonimamos D6.

Os discursos selecionados, apesar de terem sido produzidos em contextos diferentes, não foram escolhidos aleatoriamente. Em todos eles, o enunciador fala da sua política de governo, do futuro do país, de seus objetivos e de suas promessas e do seu comprometimento com as responsabilidades adquiridas com o poder.

Os discursos políticos, de um modo geral, têm sua eficácia representada na capacidade de persuadir, na busca de convencer, como já foi dito. A escolha desse tipo de discurso se justifica pelo fato de o discurso político apresentar uma relação com a atitude do falante, ou seja, favorece expressões com valores epistêmicos que, por sua vez, exercem papel importante na construção da persuasão.

\section{A MANIFESTAÇÃO DOS MODALIZADORES E O CORPUS EM ANÁLISE}

\subsection{A MANIFESTAÇÃO DOS MODALIZADORES}

Segundo Saint-Pierre (1991), com seu modelo de descrição dos modalizadores para o francês, distinguimos os modalizadores em quatro classes: os marcadores prosódicos, que são a entonação, duração vocálica etc; os marcadores morfológicos e sintáticos, que são os auxiliares modais, verbos de significação plena, adjetivos, advérbios modais e substantivos;

\footnotetext{
${ }^{3}$ Os sites consultados estão citados no final do trabalho, nas Referências Bibliográficas. Nucleus, v.8, n.2, out.2011
} 
os marcadores discursivos, que podem ultrapassar o quadro da proposição (repetição, discurso direto, extensão frástica) ou podem indicar convenções do emprego da língua (atos indiretos, fórmulas de polidez); e os marcadores metalingüísticos, que são as ligações contextuais/organização textual (acordo, desacordo, justificativa etc).

Dessas quatro classes de modalizadores apresentadas acima, optamos por analisar os marcadores morfológicos e sintáticos, por serem extremamente produtivos na língua portuguesa e principalmente no ato do discurso político.

O falante ao fazer a avaliação de um estado-de-coisas, adapta os conteúdos conforme suas marcas de julgamento e pode optar por não indicar o tipo de evidência que possui. Essa avaliação pode ser expressa por meios gramaticais ou por meios lexicais.

Os auxiliares modais dever e poder, são exemplos de meios gramaticais que são chamados de operadores de predicação.

(16) "Estes números que estão dando aqui, meu caro Mentor-quem chegou atrasado, eu não pude citar aqui, na minha nominata- estes números são apenas uma demonstração das coisas que podem acontecer neste país." (D2)

Consideramos os verbos de significação plena acreditar, achar, supor, crer e imaginar como formas de manifestação da modalidade epistêmica por indicarem saber, crença e opinião do falante.

(17) "E nós acreditamos que o programa do Biodiesel terá para o Brasil o mesmo efeito que teve o Pro-Álcool, Edinho Motimor, nos anos 70." (D6)

Os adjetivos modalizadores como provável, possível, evidente, necessário e preciso são exemplos de meios lexicais, e são chamados de predicados adjetivais, pois ocorrem em posição predicativa.

(18) "Pode ajudar a mostrar que neste planeta desigual, é possível avançar no sentido do entendimento, quando os interesses dos diferentes e, sobretudo, dos excluídos passam a integrar efetivamente a agenda nacional." (D4)

Os advérbios (certamente, possivelmente, provavelmente) e os substantivos (certeza, dúvida, possibilidade, necessidade etc.) também são considerados modalizadores, uma vez que expressam conceitos fortemente ligados à noção do saber.

(19) "E certamente, meu caro João Avamileno, Santo André será lembrada como a primeira grande cidade brasileira a atender a totalidade das pessoas mais carentes da sua cidade, recebendo o Programa Bolsa Família, com a participação valorosa e extraordinária da Prefeitura, que assumiu a responsabilidade de garantir quatro mil famílias recendo o Bolsa Família." (D2) 
(20) “É que não existe possibilidade de o Brasil não dar certo, não existe.” (D3)

Porém, é preciso verificar também como cada um desses modalizadores descritos acima atua na língua portuguesa e quais são os efeitos comunicativos que resultam do emprego deles. A seguir, faremos uma investigação a respeito da função exercida pelos modalizadores.

\subsection{ANÁLISE DO CÓRPUS}

Neste item, verificamos como o falante, a partir de sua intenção comunicativa, explicita ou não a fonte de seu saber.

Foram analisadas, a seguir, as funções dos modalizadores nos seis discursos pronunciados pelo Presidente Luiz Inácio Lula da Silva.

Consideremos a distribuição dos modalizadores nos discursos selecionados conforme a tabela abaixo. Observa-se que há o predomínio de uma das classes modalizadoras em cada discurso.

Tabela 1: Modalizadores de Certeza e Possibilidade

$\begin{array}{llllllll}\begin{array}{l}\text { Modalizadores } \\ \text { de Certeza }\end{array} & \text { D1 } & \text { D2 } & \text { D3 } & \text { D4 } & \text { D5 } & \text { D6 } & \text { TOTAL } \\ \begin{array}{llllll}\text { Modalizadores } \\ \text { de Possibilidade }\end{array} & \text { D1 } & \text { D2 } & \text { D3 } & \text { D4 } & \text { D5 } & \text { D6 } & \text { TOTAL } \\ & 1 & 2 & 8 & 2 & 3 & 6 & 22\end{array}$

Em D1, o presidente, então eleito pelo povo brasileiro, demonstra um maior comprometimento e envolvimento com o que diz. Apoiado nos altos índices de popularidade e credibilidade, observamos que o presidente expressa seu saber fazendo uso dos modalizadores de certeza, com maior freqüência.

(21) "Trata-se de uma poderosa energia solidária que a nossa campanha despertou e que não podemos e não vamos desperdiçar. Uma energia ético-política extraordinária que nos empenharemos para que se encontre canais de expressão em nosso Governo. Por tudo isso, acredito no pacto social." (D1)

(22) "Estou convencido de que temos, dessa forma, uma chance única de superar os principais entraves ao desenvolvimento sustentado do País. E acreditem, acreditem mesmo, não pretendo desperdiçar essa oportunidade conquistada com a luta de muitos milhões e milhões de brasileiros e brasileiras." (D1) 
Em D2, ao se pronunciar em Santo André (SP) sobre a entrega dos cartões do Programa Bolsa Família, seus enunciados vêm qualificados por modalizadores de certeza e, na maioria, indicando comprometimento, evidenciado pelo uso da primeira pessoa do singular (23) e também pelo uso da primeira pessoa do plural (24) (25).

(23) "Eu estou convencido de que o Brasil se transformará num país de ponta, no país carro-chefe da produção de biodiesel, porque os Estados Unidos estão produzindo biodiesel de milho, que custa três vezes mais do que estamos produzindo." (D2)

(24) "E nós acreditamos que o programa do Biodiesel terá para o Brasil o mesmo efeito que teve o Pro-Álcool, (...).” (D2)

(25) "Mas temos clareza que, dentro desse conjunto da sociedade, tem as pessoas mais necessitadas." (D2)

Nesse discurso, observa-se que não há o aparecimento de muitos modalizadores de possibilidade/incerteza, pois o presidente tem muita segurança de seus projetos e ideais.

No discurso D3, percebe-se um uso equilibrado dos modalizadores de certeza e possibilidade. Ao tratar da construção da ferrovia Litorânea Sul, o presidente ressalta as realizações de seu governo, pois o ano de 2006 é o último ano de seu primeiro mandato e, com isso, evidencia um comprometimento e uma tentativa de manter credibilidade (26). Ao mesmo tempo, ele justifica o que não foi feito e tenta se defender. Observa-se, então, que a manifestação da modalização expressa um pouco de incerteza/possibilidade como pode ser visto em (27) e (28):

(26) "Eu acredito que todos vocês têm dimensão do evento que estamos fazendo hoje." (D3)

(27) "Bem, eu acho que a retomada da construção de ferrovias somada a tudo que estamos fazendo para recuperar as rodovias, veja um negócio, todo santo dia tinha uma crítica às rodovias." (D3)

(28) Possivelmente, todos nós sonhamos há muito tempo que o Brasil precisaria ser dotado de um modelo de infra-estrutura que pudesse permitir que o Brasil andasse mais rápido (...). E nem sempre as coisas acontecem com a rapidez com que nós gostaríamos que acontecessem. (D3)

Em D4, discurso de posse do seu segundo mandato, Lula reafirma seu comprometimento, utilizando com mais freqüência os modalizadores de certeza, como fez no primeiro discurso de posse (D1). No discurso D4, o presidente fala de ações passadas que o 
justifica como presidente, ou seja, dos quatro anos que esteve no governo. Tenta explicar suas falhas novamente comprometendo-se em corrigi-las (29), e tenta ganhar mais credibilidade à sua fala e reforçar a certeza do seu enunciado transferindo responsabilidade e envolvendo o ouvinte, (30) (31). Observa-se também, nesse discurso, que o presidente faz uso de construções impessoais para indicar mudanças que todos reconhecem como indispensáveis (32) e (33):

(29) "Tenho plena consciência do que isso significa. Sei que, a partir de hoje, cabeme corrigir o que deve ser corrigido e avançar com maior determinação no que está dando certo, para consolidar as conquistas populares." (D4)

(30) "O Brasil não pode continuar como uma fera presa numa rede de aço invisível -debatendo-se, exaurindo-se, sem enxergar a teia que o aprisiona." (D4)

(31) "O trabalhador brasileiro ainda não ganha o que realmente merece, mas temos hoje um dos mais altos salários mínimos das últimas décadas, e os trabalhadores obtiveram ganhos reais em $90 \%$ das negociações salariais nestes últimos quatro anos." (D4)

(32) "É preciso desatar alguns nós decisivos para que o país possa usar a força que tem e avançar com toda velocidade." (D4)

(33) "É preciso uma combinação ampla e equilibrada do investimento público e do investimento privado." (D4)

Nos dois últimos pronunciamentos analisados (D5) e (D6), depois de já ter superado uma grave crise envolvendo partido e políticos importantes diretamente ligados ao presidente, seu comprometimento pessoal é evidenciado pelos modalizadores de certeza, imprimindo uma idéia de responsabilidade. De todos os discursos analisados, o D6 é o que apresenta maior freqüência de uso dos modalizadores de certeza. Isso mostra a tentativa do presidente de recuperar e manter a credibilidade perdida há um tempo por conta dos escândalos envolvendo seu governo. A conseqüência é um nível de aprovação de quase $80 \%$ revelado por pesquisas.

(34) "E eu sei que quando terminar a presidência da República, aconteça o que acontecer, nós vamos estar juntos em muitas outras batalhas para melhorar a vida do povo brasileiro." (D5)

(35) "Eu sei dessas coisas, companheiros. Nós temos três anos para construir o que falta ser construído.” (D5) 
(36) "Estou convencido de que podemos criar um conceito novo de segurança para um mundo em que não só a energia, mas também as ideologias sejam renováveis." (D6)

(37) "Foi assim no passado. E estou convencido de que será assim agora. Basta que não façamos um diagnóstico equivocado do problema. Basta que não enveredemos por caminhos errados." (D6)

Mesmo nas poucas indicações de incerteza o presidente Lula as faz com comprometimento. Veja as ocorrências (38) e (39):

(38) "Acho que cada um de nós tem um nome de cidade impresso na certidão de nascimento e gravado na nossa consciência e nosso coração." (D5)

(39) "Os biocombustíveis não são o vilão que ameaça a segurança alimentar das nações mais pobres. Ao contrário, desde que desenvolvidos de forma criteriosa, de acordo com a realidade de cada país, podem ser um instrumento importante para gerar renda e retirar países da insegurança alimentar e energética. O Brasil é um exemplo disso." (D6)

Além de analisarmos formas mais freqüentes e funções dos modalizadores, percebemos outras maneiras de comprometimento e/ou descomprometimento do falante que são apontadas aqui. Verificamos a ocorrência de estruturas que denominamos "limpas", ou seja, são estruturas que não apresentam modalizador epistêmico, mas que apresentam elementos que reforçam o efeito da modalização epistêmica e a verdade do enunciado. Temos, por exemplo, orações intercaladas (40) e verbos do dizer (41) e (42):

(40) “O que distribuímos - e mais do que isso: socializamos - foi cidadania.”(D4)

(41) "Quero dizer para vocês que essa foi uma obra de engenharia que para construir a possibilidade do financiamento, nós levamos praticamente dois anos (...).” (D3)

(42) "Queria dizer para a imprensa para vocês prestarem atenção numa coisa (...)." (D5)

\section{CONCLUSÃO}

Sabendo que a modalidade epistêmica é reveladora da atitude do falante, do seu comprometimento e envolvimento com a verdade do enunciado, a análise dos discursos políticos, muito persuasivos e produtivos, evidenciou graus diferentes de comprometimento 
do enunciador com o que foi dito, com o conteúdo de seu enunciado, e também uma variação de manifestações dos modalizadores epistêmicos.

Por meio da análise do corpus pudemos observar que o uso dos modalizadores epistêmicos é determinado pelas intenções comunicativas do falante. Os discursos analisados apontam para uma necessidade de convencimento e comprometimento do falante em praticamente todos os momentos políticos representados. Os dados analisados demonstram um maior grau de certeza e um menor grau de possibilidade/incerteza na fala do atual Presidente da República, Luiz Inácio Lula da Silva, e em todos esses momentos há o comprometimento e o envolvimento do falante com aquilo que é dito.

Encontramos, além dos modalizadores estudados, formas que envolvem o falante como, por exemplo, as estruturas desprovidas de modalizador como os verbos de dizer e orações intercaladas que reforçam o efeito de sentido epistêmico do enunciado.

Sabedores da importância do estudo sobre a linguagem, de suas surpreendentes descobertas e também de certas armadilhas, esperamos que as reflexões feitas nesse trabalho, ainda que muito preliminares, sirvam para contribuir, modestamente, para o estudo e entendimento do vasto campo das modalidades.

\section{REFERÊNCIAS}

CORACINI, M. J. Um fazer persuasivo: o discurso subjetivo da ciência. São Paulo: Educ; Campinas: Pontes, 1991.

DALL'AGLIO-HATTNHER, M. M. A manifestação da modalidade epistêmica: um exercício de análise nos discursos do ex-presidente Collor. 1995, 146f. Tese (Doutorado em Estudos Lingüísticos e Língua Portuguesa) - Universidade Estadual Paulista, Araraquara.

DIK, S. C. The Teory of Functional Grammar. Pt. I: The Structure of the clause. Dordrecht-Holand/Providence RI-USA: Foris Publication, 1989.

DUCROT, O. O dizer e o dito. Polifonia da enunciação. Barcelona, Paidos, 1986.

FANTINATI, C. E. Sobre o Discurso Político. Alfa, São Paulo, v. 34, 1990, p.1-10.

FERNANDES, F.; LUFT, C. P. Dicionário Brasileiro Globo. São Paulo: Marques Guimarães, 1996.

FIORIN, J. L. O Regime de 1964 - Discurso e Ideologia. São Paulo: Atual, 1988.

GUIRALDELLI, L. A. O modo subjuntivo e a expressão das modalidades epistêmica, deôntica e volitiva. São José do Rio Preto: 2004, 104 f. Dissertação (Mestrado em Estudos Lingüísticos - Área de Concentração em Análise Lingüística) - Instituto de Biociências, Letras e Ciências Exatas, Universidade Estadual Paulista, São Paulo. 
LIONS, J. Semantics. Combridge: Cambridge University Press, 1977. v. 2, 897p.

NEVES, M. H. M. Imprimir marcas no enunciado. Ou: A modalização na linguagem. In:

Texto e Gramática. São Paulo: Contexto, 2006, p. 151-174.

OSAKABE, H. Argumentação e discurso político. São Paulo: Kairós, 1979.

QUIRK, R. et al. A Comprehensive Grammar of the English Language. 7. ed. London: Longman, 1985.

SAINT-PIERRE, M. La modalisation en francais parlé: une analyse informatisée. Montreal: Université du Québec, 1991 (Mimeogr.).

SILVA, L. I. L. Discurso de posse do Presidente Luiz Inácio Lula da Silva: 01 jan. 2003. Disponível em: http://www.lainsignia.org/2003/enero/ibe_009.htm. Acesso em: 01 ago 2008.

SILVA, L. I. L. Discurso do Presidente Luiz Inácio Lula da Silva na Cerimônia de entrega de cartões de programa Bolsa Família: 04/05/05. Disponível em:

http://www.politicos.br.101.org/discurso-do-presidente-lula-ferroviaria-litoranea-sul.html. Acesso em: 01 ago 2008.

SILVA, L. I. L. Discurso do Presidente Luiz Inácio Lula da Silva na Construção da variante ferroviária litorânea sul: 24/01/06. Disponível em: http://www.politicos.br.101.org/discursodo-preside. Acesso em: 01 ago 2008.

SILVA, L. I. L. Discurso de posse do Presidente Luiz Inácio Lula da Silva: 02 jan. 2007. Disponível em: http://www.1.folha.uol.com.br/folha/brasil/ult96u88185.shtml. Acesso em: 01 ago. 2008.

SILVA, L. I. L. Discurso do Presidente Luiz Inácio Lula da Silva na Cerimônia de Abertura da 3a Conferência Nacional das Cidades: 26 nov. 2007. Disponível em:

http://grupobeatrice.blogspot.com/2008/06/discurso-do-presidente-lula-na-fao-roma.html. Acesso em: 01 ago. 2008.

SILVA, L. I. L. Discurso do Presidente Luiz Inácio Lula da Silva na Reunião de Alto Nível da FAO sobre segurança Alimentar, Mudanças Climáticas e Bioenergia: 03 jun.2008.

Disponível em: http://grupobeatrice.blogspot.com/2008/06/discurso-do-presidente-lula-nafao-roma.html. Acesso em: 01 ago. 2008. 
